\title{
IL-7Ra and L-selectin, but not CD103 or CD34, are required for murine peanut-induced anaphylaxis
}

\author{
Steven Maltby ${ }^{1 \dagger}$, Erin J DeBruin ${ }^{1 \dagger}$, Jami Bennett ${ }^{1 \dagger}$, Matthew J Gold ${ }^{1}$, Matthew C Tunis ${ }^{2}$, Zhiqi Jiann ${ }^{1}$ \\ Jean S Marshall ${ }^{2}$ and Kelly M McNagny ${ }^{1 *}$
}

\begin{abstract}
Background: Allergy to peanuts results in severe anaphylactic responses in affected individuals, and has dramatic effects on society and public policy. Despite the health impacts of peanut-induced anaphylaxis (PIA), relatively little is known about immune mechanisms underlying the disease. Using a mouse model of PIA, we evaluated mice with deletions in four distinct immune molecules (IL7Ra, L-selectin, CD34, CD103), for perturbed responses.

Methods: PIA was induced by intragastric sensitization with peanut antigen and cholera toxin adjuvant, followed by intraperitoneal challenge with crude peanut extract (CPE). Disease outcome was assessed by monitoring body temperature, clinical symptoms, and serum histamine levels. Resistant mice were evaluated for total and antigen specific serum IgE, as well as susceptibility to passive systemic anaphylaxis.

Results: PIA responses were dramatically reduced in IL7Ra ${ }^{-/-}$and $\mathrm{L}-$ selectin ${ }^{-/}$mice, despite normal peanut-specific IgE production and susceptibility to passive systemic anaphylaxis. In contrast, $\mathrm{CD} 34^{-/-}$and $\mathrm{CD}_{103^{-/}}$ mice exhibited robust PIA responses, indistinguishable from wild type controls.

Conclusions: Loss of L-selectin or IL7Ra function is sufficient to impair PIA, while CD34 or CD103 ablation has no effect on disease severity. More broadly, our findings suggest that future food allergy interventions should focus on disrupting sensitization to food allergens and limiting antigen-specific late-phase responses. Conversely, therapies targeting immune cell migration following antigen challenge are unlikely to have significant benefits, particularly considering the rapid kinetics of PIA.
\end{abstract}

Keywords: Anaphylaxis, Animal model, Food allergy, Immunity, Peanut allergy

\section{Introduction}

Food allergies affect a significant portion of the population, with direct effects on health and quality of life. Of all food sensitivities, peanut allergies account for the most fatalities [1] and exposure to peanut antigen in affected individuals results in severe, rapid, systemic anaphylactic responses. Despite the severity of peanut anaphylactic responses, few effective treatments or therapies exist and most focus on limiting allergen exposure and management of symptoms. While peanut allergy prevalence is relatively low (estimated $\sim 1-2 \%$ of the total population), the consequences of exposure are high and

\footnotetext{
* Correspondence: kelly@brc.ubc.ca

${ }^{\dagger}$ Equal contributors

'The Biomedical Research Centre, University of British Columbia, Vancouver, BC, Canada

Full list of author information is available at the end of the article
}

the effects of peanut allergy are disproportionately large in society $[2,3]$.

In affected individuals, peanut-specific IgE antibodies bind to FceR on mast cells and basophils, and are cross linked by peanut antigens, resulting in rapid release of immune mediators including histamine, leukotrienes, prostaglandins and platelet-activating factor following exposure (as reviewed in [4]). These mediators contribute to a range of pathological symptoms, including increased vascular permeability (resulting in localized edema, decreased blood pressure, and rapid decrease in body temperature), diarrhea and vomiting, and fatal respiratory failure without treatment.

To explore mechanisms underlying this pathology, a mouse model of peanut-induced anaphylaxis (PIA) was established, which closely approximates the clinical symptoms and pathology observed in peanut-allergic

\section{Biomed Central}


individuals [5]. Mice are sensitized by weekly oral feedings of peanut antigen with adjuvant. Subsequent interperitoneal challenge with peanut protein results in rapid mast cell degranulation, elevated serum histamine, and decreases in blood volume and body temperature. This model has been utilized successfully to highlight the role of B cells, CD40 ligand and mast cells and the effects of therapeutic interventions (blocking histamine and/or platelet activating factor) on peanut-induced anaphylactic responses $[5,6]$. In a related fatal PIA model, the importance of mast cells, macrophages, IgG and IgE have also been reported [7]. Similarly, in an adjuvant based model of PIA, treatment by a CD4 blockade could provide protection from disease, by increasing the frequency of $\mathrm{T}_{\text {reg }}$ [8]. However, no studies have focussed on other adaptive immune molecules, including molecules regulating immune cell migration or adhesion, in the PIA model.

In our study, we provide the first analysis of four immune molecules (IL7R $\alpha$, L-selectin, CD34, CD103) in the PIA model, to determine the effect of altered adaptive responses and cell migration on food-induced anaphylaxis. IL7R $\alpha$ (CD127) is expressed on lymphoid cells and plays key roles in regulating lymphoid development, survival and proliferation [9-11]. L-selectin (CD62L) is constitutively expressed on leukocytes and involved in neutrophil extravasation [12], lymphocyte rolling and migration into lymph nodes [13] and pathology associated with $\mathrm{T}$ cell-mediated inflammation in a number of disease models $[14,15]$. CD34 is widely used as a clinical marker for the enrichment of human hematopoietic stem cells and a marker of pluripotency. However, CD34 is also expressed by a range of hematopoietic cells and vascular endothelia and promotes optimal immune cell migration (particularly for mast cells, eosinophils and dendritic cells) and the maintenance of vascular integrity [16-20]. CD103 (integrin alpha E) is expressed on subsets of dendritic cells (DCs) and lymphocytes within the gut tissues, where it acts as an E-cadherin ligand and has been proposed as a key molecule regulating oral tolerance (detailed by Scott et al. [21]).

Here we have performed a survey of mice deficient in these immunoreceptors to identify pathways that alter susceptibility to PIA. Our findings demonstrate that ablation of either IL7R or L-sel dramatically reduces the severity of PIA, whereas ablation of two migrationassociated immune genes, $C d 34$ or $C d 103$, has no effect. These findings suggest that L-selectin and IL-7R/ play key roles in the development of adaptive immune responses to peanut antigen, while immune cell migration via CD34 or CD103-dependent mechanisms are not required. When considering effective points of intervention in PIA, our findings suggest minimal benefit in targeting late-phase immune cell migration.

\section{Materials and methods}

Mice

C57BL/6, CD103 $\left(\mathrm{Cd}_{103^{-/-}}\right)$and IL-7 receptor $\left(I L 7 R^{-/-}\right)$

deficient mice were purchased from The Jackson Laboratory. $I L 7 R^{-/-}$mice were backcrossed onto a Ly5.1

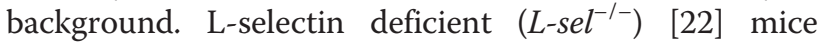
were provided by Dr. H.J. Ziltener and CD34 deficient $\left(C d 34^{-/-}\right)$mice [23] were provided by Dr. T.W. Mak. All animals were housed and bred in specific pathogen-free conditions at The BRC. For all experiments, eight to ten week old sex-matched mice were used and the Committee on Animal Care at UBC approved all procedures, in accordance with the requirements of the Canadian Council on Animal Care.

\section{Peanut-induced anaphylaxis (PIA)}

PIA was induced as previously described [5]. Briefly, mice were sensitized by oral gavage with $1 \mathrm{mg}$ peanut protein (Kraft Naturals peanut butter) and $10 \mu \mathrm{g}$ cholera toxin (List Biological Laboratories) in $100 \mu \mathrm{L}$ sterile $\mathrm{dH}_{2} \mathrm{O}$, weekly for 4 weeks. Control mice received PBS alone. Two weeks after the final sensitization, mice were challenged by intraperitoneal injection of $5 \mathrm{mg}$ crude de-fatted peanut extract (CPE; Greer Laboratories) in $500 \mu \mathrm{L}$ PBS.

\section{Clinical scoring}

Symptoms were evaluated using the scoring system described previously [5]. Animals were housed individually and observed for temperature decreases and development of clinical symptoms for 40 minutes postchallenge. Rectal temperatures were measured using a traceable expanded range digital thermometer (VWR) at 10-minute intervals. Clinical scores were assigned from $0-5$, where $0=$ no symptoms, $1=$ repetitive scratching of the ear canals, 2 = decreased activity or puffiness of the eyes, 3 = periods of motionlessness for $>1$ minute, $4=$ no response to whisker stimuli/prodding and $5=$ early endpoint triggered by seizures or convulsion.

\section{Blood analysis (Histamine, Total IgE and IgE-mediated CPE binding)}

Blood was collected via cardiac puncture from anaesthetized animals and diluted in 50ul PBS containing 2.5U of heparin. Plasma was separated by centrifugation and stored at -20C. Histamine levels were determined using an enzyme immunoassay kit (Beckman Coulter / Immunotech). Total IgE was assessed by ELISA using a murine total IgE kit (BD Pharmingen, San Diego CA). IgE-mediated CPE binding was assessed using a sandwich ELISA, similar to the protocol previously described [5]. Briefly, plates were coated with anti-mouse IgE Ab (Southern Biotech) overnight. Diluted serum samples were then incubated overnight, coated with biotinylated 
CPE (Greer), followed by streptavidin-alkaline phosphatase (Invitrogen) and developed with a commercial ELISA amplification system (Invitrogen). Resulting optical densities were adjusted to a standard curve of biotinylated $\mathrm{CPE}$.

\section{Passive systemic anaphylaxis (PSA)}

PSA was performed as previously described [24]. For histamine assessment, mice were sensitized by intravenous injection of $2 \mu \mathrm{g}$ of anti-DNP IgE (Sigma-Aldrich) in $200 \mu \mathrm{l} \mathrm{HBSS}$. For body temperature assessments, mice were sensitized with $60 \mu \mathrm{g}$ of anti-DNP IgE (in-house, clone SPE-7) in $200 \mu \mathrm{l} \mathrm{HBSS}$. Anaphylaxis was induced the next day by intravenous injection of $0.5-1.0 \mathrm{mg}$ DNP-HSA in $200 \mu \mathrm{L}$ HBSS. Anaphylaxis severity was assessed by measuring rectal temperatures at 5-minute intervals for 60 minutes or assessment of serum histamine levels 5 minutes post-injection.

\section{Statistical analysis}

$P$ values were calculated using unpaired two-way Student's $t$ test.

\section{Results}

Reduced PIA pathology in $I L 7 R^{-/-}$and $L-\mathrm{sel}^{-/-}$mice, but not $\mathrm{Cd} 34^{-/-}$or $\mathrm{Cd}_{103^{-/-}}$mice

Initially, we performed a survey of $\mathrm{ILTR}^{-/-}, \mathrm{L}-\mathrm{sel}^{-/-}$, $C d 34^{-/-}$and $C d 103^{-/-}$mice to determine susceptibility to PIA. As previously reported, naïve mice challenged with $\mathrm{CPE}$, regardless of genotype, did not exhibit any significant changes in body temperature, clinical symptoms or histamine levels when compared to control mice (Figure 1 and data not shown) [5]. To further understand of B cell and T cells in PIA [5], we assessed disease susceptibility in $I L 7 R^{-/-}$mice, which exhibit major defects in lymphoid development [9-11]. In wildtype (Ly5.1) mice, antigen challenge resulted in rapid decreases in body temperature (Figure 1A), observable clinical symptoms (Figure 1B) and elevated serum histamine (Figure $1 C$ ). In sharp contrast, $I L 7 R^{-/-}$mice were protected from disease, exhibiting limited or no decrease in body temperature (Figure 1A), no clinical symptoms (Figure 1B) and reduced histamine levels (Figure 1C).

We next assessed PIA in $\mathrm{L}_{-} \mathrm{Sel}^{-/-}$mice, as L-selectin is required for homing and migration of naïve lymphocytes and inflammatory immune cells in allergic models [13,25-27]. As such, we hypothesized L-selectin plays a role during either the sensitization stage or antigen challenge stage of disease. Following intraperitoneal challenge, $\mathrm{L}_{\text {-sel }} \mathrm{C}^{-/}$mice exhibited a minimal temperature drop (Figure 1D), which recovered by the 40-minute endpoint, and exhibited lower average clinical scores
(Figure 1E), compared to wild type controls. However, at the endpoint, $\mathrm{L}-\mathrm{sel}^{-/-}$mice exhibited elevated levels of serum histamine (Figure $1 \mathrm{~F}$ ) equivalent to wild type controls.

CD34 plays a key role in mast cell migration and development of allergic asthma [16,17], so we hypothesized that $C d 34^{-/-}$mice would also be protected from PIA. However, following challenge, $C d 34^{-/-}$mice exhibited equivalent decreases in body temperature (Figure 2A), clinical scores (Figure 2B) and serum histamine levels (Figure 2C) to wildtype control mice.

CD103 is expressed on immune cells within the gut mucosa and is a marker of DCs that maintain oral tolerance [21]. Following PIA induction, like $C d 34^{-/-}$mice, $\mathrm{Cd}_{103^{-/-}}$mice exhibited wildtype decreases in body temperature (Figure 2A), clinical symptoms (Figure 2B) and serum histamine levels (Figure 2C). From this initial screen, we determined that IL7R $\langle\forall$ and L-selectin are critical for PIA, but neither CD34, nor CD103, play major roles in the development of peanut-specific immunity or resulting anaphylactic responses following antigen exposure.

Wildtype levels of total and antigen-specific lgE in $I L 7 R^{-/-}$ and $\mathrm{L}-\mathrm{sel}^{-1-}$ mice

As disease progression was impaired in $I L 7 R^{-/-}$and

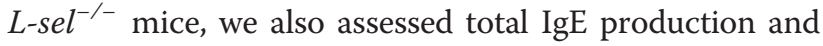
peanut-specific IgE binding in these animals. Surprisingly, despite decreased disease severity and histamine release, both $I L 7 R^{-/-}$and $L-\mathrm{sel}^{-/-}$mice exhibited normal or increased total plasma IgE levels, compared to wildtype controls (Figure 3A,B) and normal levels of IgEmediated CPE binding (Figure 3C,D). Thus, reduced disease severity in $I L 7 R^{-/-}$and $\mathrm{L}-\mathrm{sel}^{-/-}$mice is independent of the ability to produce peanut-specific IgE responses and may reflect lower affinity IgE production or otherwise impaired immune responses.

\section{${\mathrm{L}-s e l^{-/-} \text {and IL7R }}^{-/-}$mice are fully susceptible to passive system anaphylaxis (PSA)}

L-selectin and IL7R $\langle\forall$-deficient animals exhibited decreased susceptibility to PIA, which could result from impaired immune sensitization or impaired anaphylactic responses. To test the latter possibility, we assessed the susceptibility of $L-\mathrm{Sel}^{-/-}$and $I L 7 R^{-/-}$mice to a PSA model. Mice were loaded with anti-DNP IgE and challenged with DNP-HSA. After challenge, both $\mathrm{L}-\mathrm{Sel}^{-/-}$and $I L 7 R^{-/-}$exhibited marked decreases in body temperature, which recovered to initial body temperatures, similar to their respective wildtype $\mathrm{Bl} / 6$ and Ly5.1 controls (Figure 4A,D) and individual maximal temperature decreases were indistinguishable across genotypes (Figure 4B,E). Further, assessment of serum histamine levels 


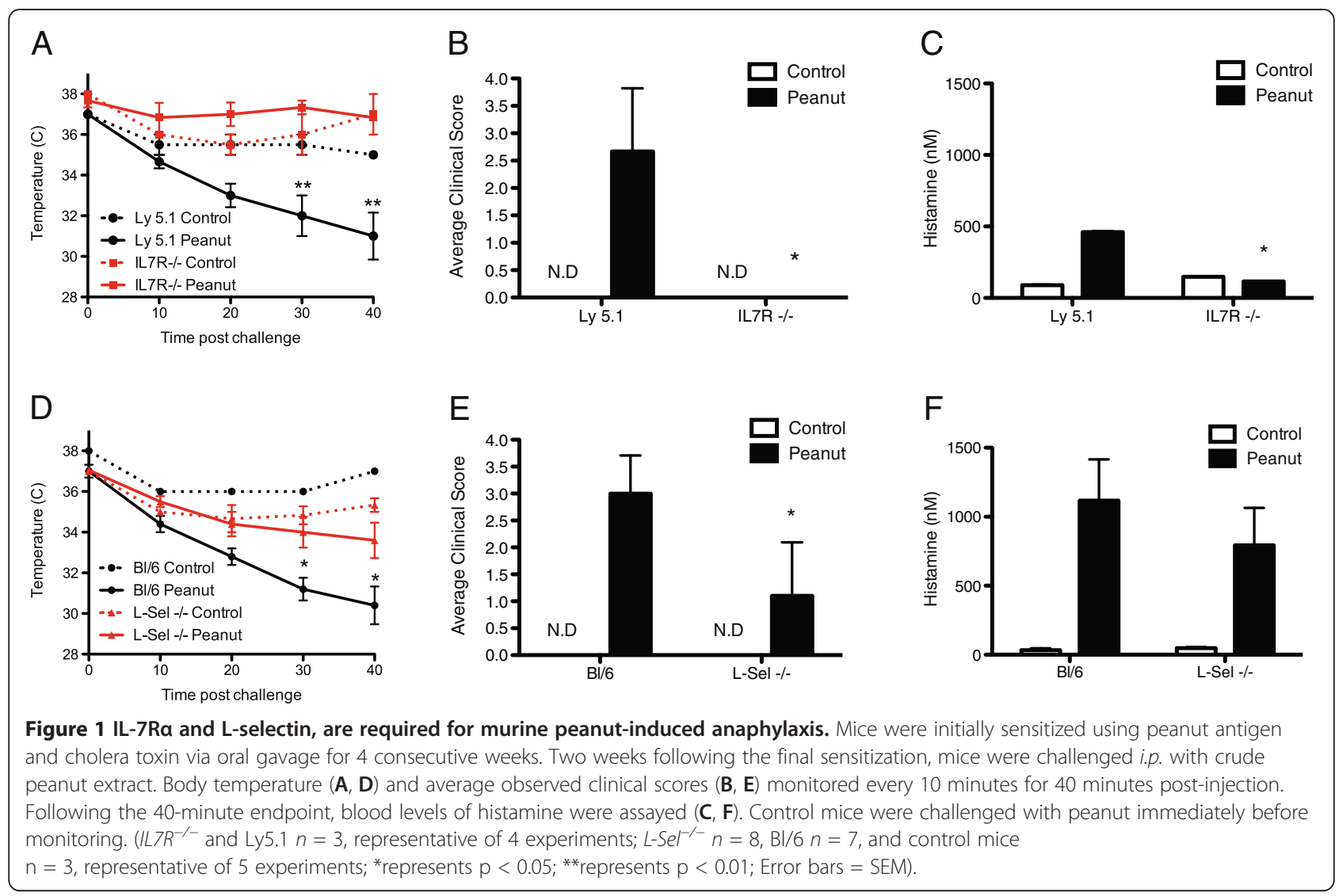

5 minutes post-challenge revealed equivalent levels of histamine release in all animals tested (Figure 4C,F). These findings demonstrate that while $L$-sel ${ }^{-/-}$and $I L 7 R\langle\forall$ mice are protected from PIA, both strains are capable of mounting a robust systemic anaphylactic response when loaded with equivalent levels of antigen-specific IgE.

\section{Discussion}

Peanut-induced anaphylaxis is a severe medical condition, with major effects on individual patient health and social policy. Despite this, we lack a basic understanding of unique underlying mechanisms of the disease. Recent studies using a mouse model of PIA have highlighted

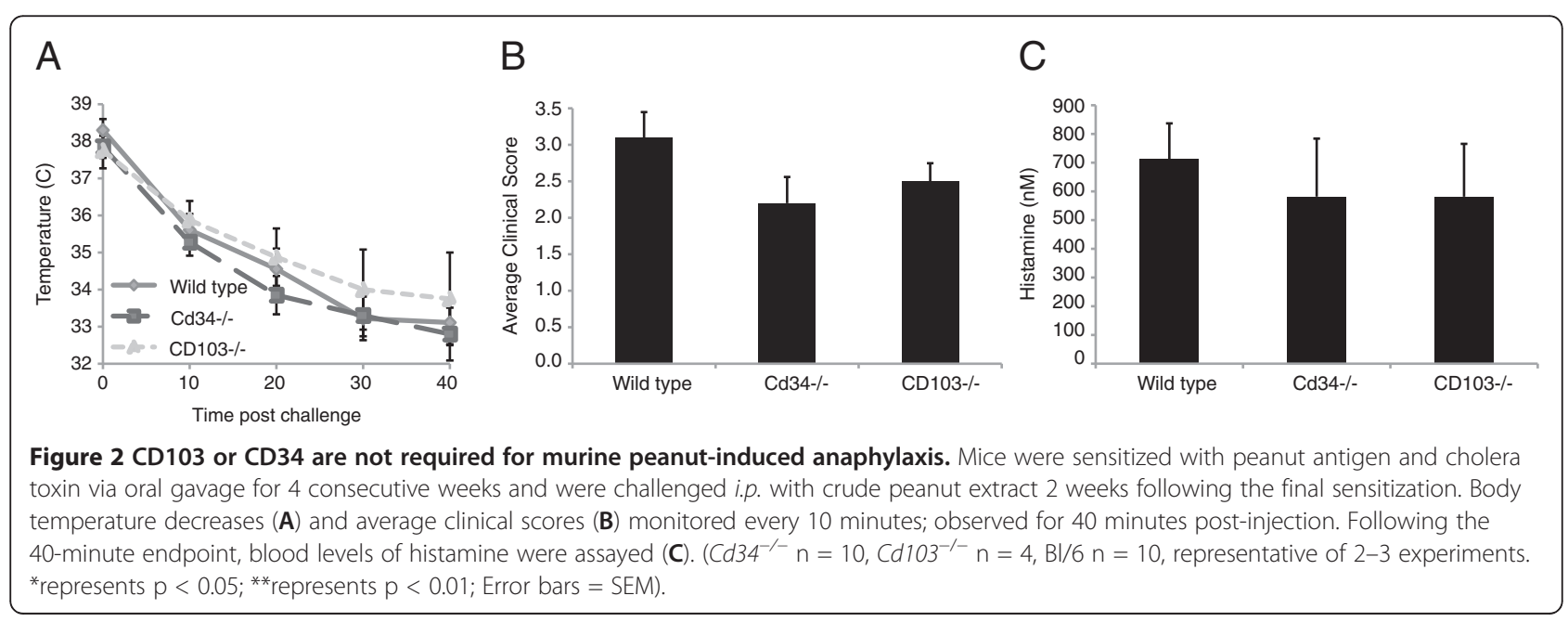




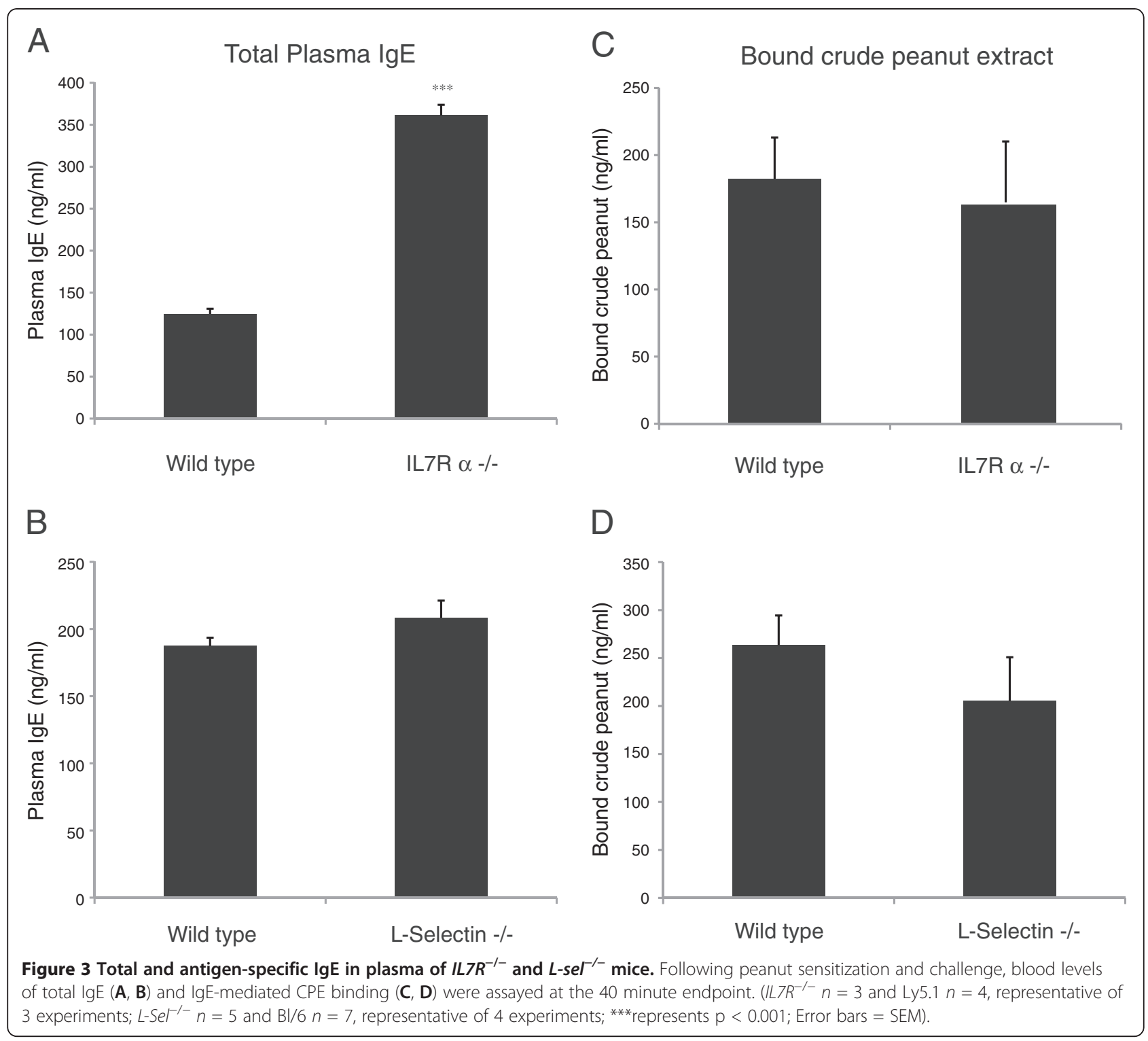

the role of B cells in peanut allergy development or focussed on potential therapeutic interventions [5-7]. However, the importance of other specific immune molecules and immune processes underlying this disease are not well understood. In the current study, we used a series of knockout mice to survey the importance of cytokine receptors and adhesion/trafficking molecules in susceptibility to food allergy with the goal of identifying novel pathways as points of therapeutic intervention.

We were surprised to find that ablation of CD34 had no effect on PIA, since this molecules has previously been shown to play critical roles in a variety of immune cell mediated disease models $[16,18,28,29]$. One possible explanation is that after priming is complete, cell trafficking no longer plays a role in the effector phase of PIA due to the short timeline of disease ( 1 hour).
Although CD34 facilitates the migration of several hematopoietic effector lineages (mast cells, eosinophils and DCs) and $C d 34^{-/-}$mice are protected in models of asthma, ulcerative colitis and hypersensitivity pneumonitis, this likely reflects a delay, but not a block, in the ability of CD34 ${ }^{+}$effector cells to migrate $[16,18,28,29]$. Thus, given sufficient time for priming, it is likely that these mice "catch up" to their wildtype counterparts and are equally susceptible to the acute phase of an anaphylactic response.

CD103 is an E-cadherin ligand proposed to specify tissue localization of $\mathrm{CD}_{103^{+}} \mathrm{DCs}$ and mucosal T cells within the gut [30-34]. CD103 ${ }^{+}$DCs promote both $\mathrm{T}_{\text {reg }}$ development and $\mathrm{T}_{\text {eff }}$ cell homing [30,32], and play a key role in maintaining oral tolerance and gut homeostasis. Notably, while CD103 is a marker of $\mathrm{T}_{\text {reg }}$ subsets, recent 


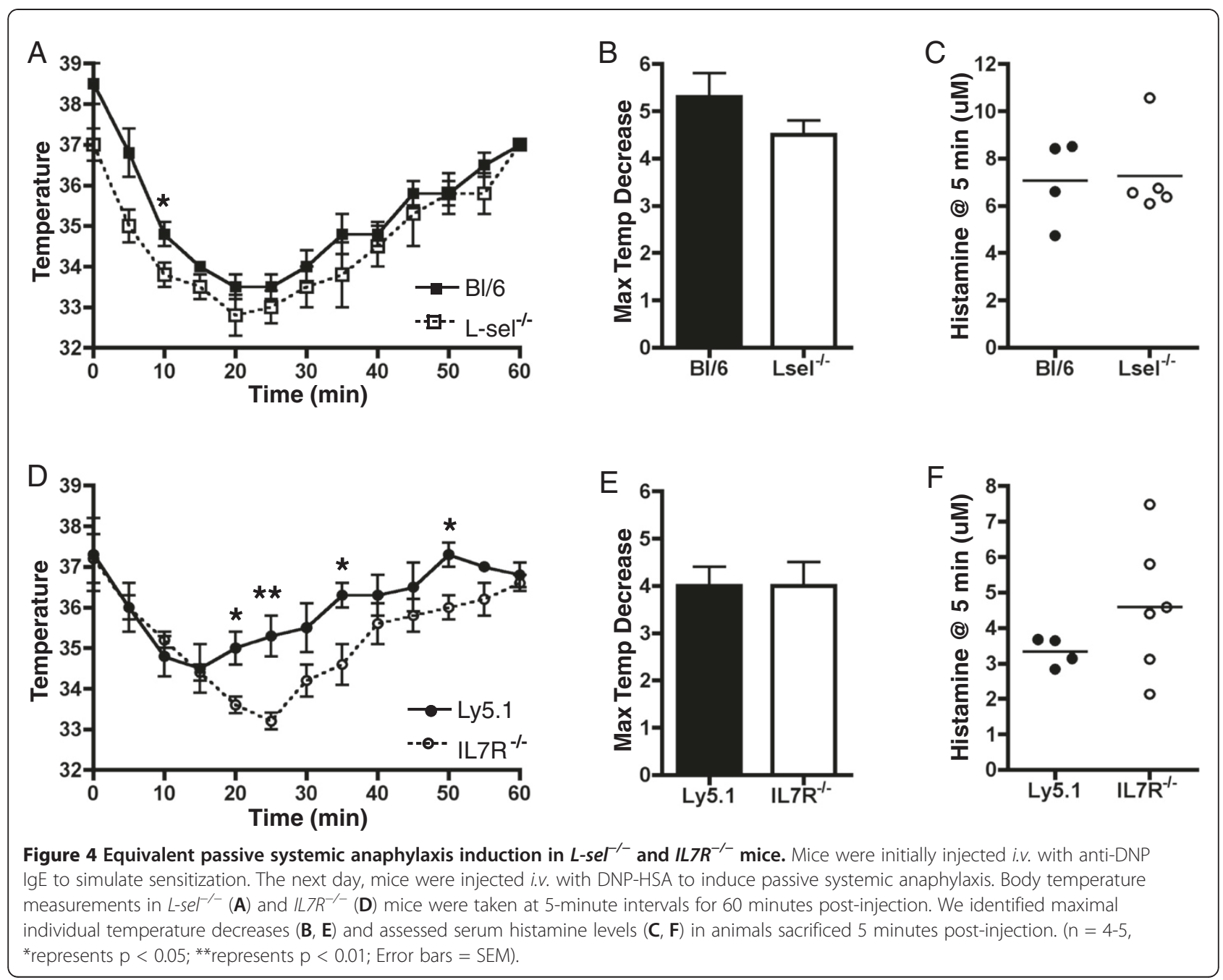

work has demonstrated that CD103 does not play an essential role in $\mathrm{T}_{\text {reg }}$ mediated functions in the gut. Mullaly et al., demonstrated that CD103 was not required for immune responses during helminth infection, and that mice which lack CD103 have normal levels of $\mathrm{T}_{\text {reg }}$ in the mesenteric lymphnodes or lamina propria [35]. CD103 is also a marker of pro-regulatory DCs, however very little work has focused on the functional role of CD103 on these cells. Therefore we and others [21], hypothesized that Cd103 ablation would exacerbate disease, if pro-regulatory DCs modulate disease severity. Our findings demonstrate, however, that loss of CD103 has no effect on PIA disease severity and, thus, we propose that CD103 is a valuable marker of DC and $\mathrm{T}_{\text {reg }}$ subsets in the gut, but does not play an essential role in the development or maintenance of oral tolerance.

Our findings demonstrate that disease severity is reduced when adaptive immune responses are impaired. This is particularly evident in $I L 7 R^{-/-}$mice, which exhibit severe defects in lymphoid development and survival, resulting in lymphopenia, low thymic cellularity and impaired antibody production [9-11]. Surprisingly, despite severe defects, $I L 7 R^{-/-}$mice produce normal serum Ig levels [36] and in the PIA model had wildtype (or elevated) levels of both total IgE and antigen-specific IgE. Nevertheless, $I L 7 R^{-/-}$mice exhibited reduced circulating histamine levels following peanut challenge. This apparent discrepancy may reflect a severely limited antibody repertoire in $I L 7 R^{-/-}$mice [37]. Without effective IL-7R signalling, distal regions of the immunoglobulin heavy chain loci become inaccessible, resulting in limited $\mathrm{B}$ cell repertoires and, likely, lower affinity antibody production [37]. In vivo, lower affinity antibodies likely fail to induce a robust histamine release (despite normal IgE levels), resulting in an absence of clinical symptoms in the PIA model. This finding is consistent with the known role of adaptive immunity in allergic responses, and the importance of B cells reported in this model [5]. 
The degree of protection from PIA was more subtle in $\mathrm{L}_{\text {-sel }}{ }^{-/}$mice, which exhibit an attenuated response. $\mathrm{L}$-selectin is involved in adaptive immunity both in naïve $\mathrm{T}$ cell homing and the migration of mature Ag-specific $\mathrm{T}$ cells during inflammation [12-14,26,27]. $\mathrm{L}-\mathrm{sel}^{-/-}$mice mount a normal antibody response [14], but are protected in a number of acute inflammatory and T-cell mediated models of delayed-type hypersensitivity reaction and experimental allergic encephalomyelitis [14,15,25-27]. Intriguingly, despite reduced disease pathology in $\mathrm{L}-\mathrm{sel}^{-/}$ mice, no difference in blood histamine or IgE levels was observed following PIA-induction, suggesting that they may represent an asymptomatic sensitization to peanut allergen [38]. Our findings also suggest that protection in $\mathrm{L}_{-} \mathrm{sel}^{-/-}$mice is via a histamineindependent mechanism, (most likely regulating $\mathrm{T}$ cell or neutrophil recruitment and migration). Intriguingly, despite the reduced susceptibility to PIA, both $I L 7 R^{-I-}$ and $\mathrm{L}_{\text {-sel }} \mathrm{Cl}^{-/-}$mice exhibited normal susceptibility to passive systemic anaphylaxis.

In summary, we have shown that targeting L-selectin or IL7R $\langle\forall$ function is sufficient to reduce PIA responses, while loss of CD34 or CD103 has no effect on disease severity. More broadly, these findings suggest that interventions targeting initial immune sensitization are more likely to meet with therapeutic success, by suppressing effective antigen-specific antibody production and inhibiting late-phase anaphylaxis/mast cell responses. Conversely, therapies inhibiting immune cell migration following antigen challenge are unlikely to have significant benefits, particularly considering the rapid kinetics of peanut-induced anaphylaxis.

\section{Conflict of interest}

No conflict of interest is declared by any authors of this manuscript.

\section{Authors' contributions}

$S M$ and JB designed and performed all experiments and wrote the manuscript. EDB coordinated reagent procurement and initiation of the project, participated in experiment harvests and edited the manuscript. MJG, $M C T$, and ZJ performed selected assays and edited the manuscript. JSM and KMM supervised trainees, edited the manuscript, and provided reagents. All authors read and approved the final manuscript.

\footnotetext{
Acknowledgements

We are grateful to Takahide Murakami for genotyping, Hermann J. Ziltener for providing $I L 7 R^{-/-}$and $\mathrm{Lsel}^{-/-}$mice, Helen Merkens and Kimberley Allan for technical support, and the BRC Animal Care Facility for animal handling. This work was funded by grants from the Canadian Group on Food Allergy Research (CanGoFar; Grant \#07B1), the AllerGen Network NCE and the Canadian Institutes of Health Research (CIHR; MOP-84545). SM was supported through a CIHR and Heart and Stroke Foundation of Canada Fellowship from the Centre for Blood Research (CBR), JB was supported by the Multiple Sclerosis Society of Canada, EJD was supported through a NSERC Postgraduate Scholarship and a UBC 4-Year Fellowship and MJG holds a fellowship from the CIHR/Michael Smith Foundation for Health Research (MSFHR) Transplantation Training Program. KMM is a MSFHR Scholar (Senior) and CBR Member.
}

\section{Author details}

'The Biomedical Research Centre, University of British Columbia, Vancouver, BC, Canada. ${ }^{2}$ Department of Microbiology \& Immunology, Dalhousie University, Halifax, NS, Canada.

Received: 13 June 2012 Accepted: 14 August 2012

Published: 31 August 2012

\section{References}

1. Bock SA, Muñoz-Furlong A, Sampson HA: Further fatalities caused by anaphylactic reactions to food, 2001-2006. J Allergy Clin Immunol 2007, 119:1016-1018.

2. Kagan RS, Joseph L, Dufresne C, Gray-Donald K, Turnbull E, Pierre YS, Clarke AE: Prevalence of peanut allergy in primary-school children in Montreal, Canada. J Allergy Clin Immunol 2003, 112:1223-1228.

3. Sicherer SH, Muñoz-Furlong A, Sampson HA: Prevalence of peanut and tree nut allergy in the United States determined by means of a random digit dial telephone survey: a 5-year follow-up study. J Allergy Clin Immunol 2003, 112:1203-1207.

4. Galli SJ, Tsai M, Piliponsky AM: The development of allergic inflammation. Nature 2008, 454:445-454.

5. Sun J, Arias K, Alvarez D, Fattouh R, Walker T, Goncharova S, Kim B, Waserman S, Reed J, Coyle AJ, Jordana M: Impact of CD40 Ligand, B Cells, and mast cells in peanut-induced anaphylactic responses. J Immunol 2007, 179:6696-6703.

6. Arias K, Baig M, Colangelo M, Chu D, Walker T, Goncharova S, Coyle A, Vadas $\mathrm{P}$, Waserman $\mathrm{S}$, Jordana M: Concurrent blockade of plateletactivating factor and histamine prevents life-threatening peanut-induced anaphylactic reactions. J Allergy Clin Immunol 2009, 124:307-314. e2.

7. Arias K, Chu DK, Flader K, Botelho F, Walker T, Arias N, Humbles AA, Coyle AJ, Oettgen HC, Chang H-D, Van Rooijen N, Waserman S, Jordana M: Distinct immune effector pathways contribute to the full expression of peanut-induced anaphylactic reactions in mice. J Allergy Clin Immunol 2011, 127:1552-1561. e1.

8. Duarte J, Caridade M, Graca L: CD4-blockade can induce protection from peanut-induced anaphylaxis. Front Immunol 2011, 2:1-9.

9. Peschon J, Morrissey P, Grabstein K, Ramsdell F, Maraskovsky E, Gliniak B: Early lymphocyte expansion is severely impaired in interleukin 7 receptor-deficient mice. J Exp Med 1994, 180:1955-1960

10. Maki K, Sunaga S, Komagata Y, Kodaira Y, Mabuchi A, Karasuyama H, Yokomuro K, Miyazaki Jl, Ikuta K: Interleukin 7 receptor-deficient mice lack gammadelta T cells. PNAS 1996, 93:7172-7177.

11. Jacobs SR, Michalek RD, Rathmell JC: IL-7 Is essential for homeostatic control of $\mathrm{t}$ cell metabolism in vivo. J Immunol 2010, 184:3461-3469.

12. Hickey MJ, Forster M, Mitchell D, Kaur J, De Caigny C, Kubes P: L-selectin facilitates emigration and extravascular locomotion of leukocytes during acute inflammatory responses in vivo. J Immunol 2000, 165:7164-7170.

13. Arbonés ML, Ord DC, Ley K, Ratech H, Maynard-Curry C, Otten G, Capon DJ, Teddert TF: Lymphocyte homing and leukocyte rolling and migration are impaired in L-selectin-deficient mice. Immunity 1994, 1:247-260.

14. Catalina MD, Carroll MC, Arizpe H, Takashima A, Estess P, Siegelman MH: The route of antigen entry determines the requirement for l-selectin during immune responses. J Exp Med 1996, 184:2341-2352.

15. Grewal IS, Foellmer HG, Grewal KD, Wang H, Lee WP, Tumas D, Janeway CA $\mathrm{Jr}$, Flavell RA: CD62L is required on effector cells for local interactions in the CNS to cause myelin damage in experimental allergic encephalomyelitis. Immunity 2001, 14:291-302.

16. Blanchet MR, Maltby S, Haddon DJ, Merkens H, Zbytnuik L, McNagny KM: CD34 facilitates the development of allergic asthma. Blood 2007, 110:2005-2012.

17. Drew E, Merzaban JS, Seo W, Ziltener HJ, MCNagny KM: CD34 and CD43 inhibit mast cell adhesion and are required for optimal mast cell reconstitution. Immunity 2005, 22:43-57.

18. Blanchet M-R, Bennett JL, Gold MJ, Levantini E, Tenen DG, Girard M, Cormier Y, MCNagny KM: CD34 is required for dendritic cell trafficking and pathology in murine hypersensitivity pneumonitis. Am J Respir Crit Care Med 2011, 184:687-698.

19. Maltby S, Freeman S, Gold MJ, Baker JHE, Minchinton Al, Gold MR, Roskelley CD, McNagny KM: Opposing roles for CD34 in B16 melanoma tumor growth alter early stage vasculature and late stage immune cell infiltration. PLoS One 2011, 6:e18160. 
20. Blanchet M-R, Gold M, Maltby S, Bennett J, Petri B, Kubes P, Lee DM, McNagny KM: Loss of CD34 leads to exacerbated autoimmune arthritis through increased vascular permeability. J Immunol 2010, 184:1292-1299.

21. Scott CL, Aumeunier AM, Mowat AM: Intestinal CD103+ dendritic cells: master regulators of tolerance? Trends Immunol 2011, 32:412-419.

22. Borsig L, Wong R, Hynes RO, Varki NM, Varki A: Synergistic effects of L- and P-selectin in facilitating tumor metastasis can involve non-mucin ligands and implicate leukocytes as enhancers of metastasis. PNAS 2002, 99:2193-2198.

23. Suzuki A, Andrew D, Gonzalo J, Fukumoto M, Spellberg J, Hashiyama M, Takimoto H, Gerwin N, Webb I, Molineux G, Amakawa R, Tada Y, Wakeham A, Brown J, McNiece I, Ley K, Butcher E, Suda T, Gutierrez-Ramos J, Mak T: CD34-deficient mice have reduced eosinophil accumulation after allergen exposure and show a novel crossreactive $90-\mathrm{kD}$ protein. Blood 1996, 87:3550-3562.

24. Ujike A, Ishikawa Y, Ono M, Yuasa T, Yoshino T, Fukumoto M, Ravetch JV, Takai T: Modulation of Immunoglobulin (Ig)E-Mediated Systemic Anaphylaxis by Low-Affinity Fc Receptors for IgG. J Exp Med 1999, 189:1573-1579.

25. Szántó S, Gál I, Gonda A, Glant TT, Mikecz K: Expression of L-Selectin, but Not CD44, is required for early neutrophil extravasation in antigeninduced arthritis. J Immunol 2004, 172:6723-6734.

26. Tedder TF, Steeber DA, Pizcueta P: L-selectin-deficient mice have impaired leukocyte recruitment into inflammatory sites. J Exp Med 1995, 181:2259-2264.

27. Steeber DA, Tang MLK, Green NE, Zhang X-Q, Sloane JE, Tedder TF: leukocyte entry into sites of inflammation requires overlapping interactions between the L-Selectin and ICAM-1 pathways. I Immunol 1999, 163:2176-2186.

28. Maltby S, Wohlfarth C, Gold M, Zbytnuik L, Hughes MR, McNagny KM: CD34 is required for infiltration of eosinophils into the colon and pathology associated with DSS-induced ulcerative colitis. Am J Pathol 2010, 177:1244-1254.

29. Drew E, Huettner CS, Tenen DG, McNagny KM: CD34 expression by mast cells: of mice and men. Blood 2005, 106:1885-1887.

30. Johansson-Lindbom B, Svensson M, Pabst O, Palmqvist C, Marquez G, Förster R, Agace WW: Functional specialization of gut CD103+ dendritic cells in the regulation of tissue-selective T cell homing. J Exp Med 2005, 202:1063-1073.

31. Jaensson E, Uronen-Hansson H, Pabst O, Eksteen B, Tian J, Coombes JL, Berg P-L, Davidsson T, Powrie F, Johansson-Lindbom B, Agace WW: Small intestinal CD103+ dendritic cells display unique functional properties that are conserved between mice and humans. J Exp Med 2008, 205:2139-2149.

32. Sun C-M, Hall JA, Blank RB, Bouladoux N, Oukka M, Mora JR, Belkaid Y: Small intestine lamina propria dendritic cells promote de novo generation of foxp3 $t$ reg cells via retinoic acid. J Exp Med 2007, 204:1775-1785.

33. Cepek KL, Shaw SK, Parker CM, Russell GJ, Morrow JS, Rimm DL, Brenner MB: Adhesion between epithelial cells and T lymphocytes mediated by E-cadherin and the |[alpha]|E|[beta]|7 integrin. Nature 1994, 372:190-193.

34. Karecla PI, Bowden SJ, Green SJ, Kilshaw PJ: Recognition of E-cadherin on epithelial cells by the mucosal T cell integrin aM290ß3 (aEß7). European Journal of Immunology 1995, 25:852-856.

35. Mullaly SC, Burrows K, Antignano F, Zaph C: Assessing the role of CD103 in immunity to an intestinal helminth parasite. PLOS ONE 2011, 6:e19580.

36. Erlandsson L, Licence S, Gaspal F, Lane P, Corcoran AE, Mårtensson I-L: Both the pre-BCR and the IL-7Ra are essential for expansion at the pre-BII cell stage in vivo. European Journal of Immunology 2005, 35:1969-1976.

37. Corcoran AE, Riddell A, Krooshoop D, Venkitaraman AR: Impaired immunoglobulin gene rearrangement in mice lacking the IL-7 receptor. Nature 1998, 391:904-907.

38. Assing K, Bodtger U, Poulsen LK: Seasonal dynamics of chemokine receptors and CD62L in subjects with asymptomatic skin sensitization to birch and grass pollen. Allergy 2006, 61:759-768.

\section{Submit your next manuscript to BioMed Central and take full advantage of:}

- Convenient online submission

- Thorough peer review

- No space constraints or color figure charges

- Immediate publication on acceptance

- Inclusion in PubMed, CAS, Scopus and Google Scholar

- Research which is freely available for redistribution 